\title{
Historia reciente de la educación básica y media en el caribe colombiano: el caso del Departamento del Atlántico
}

\author{
The recent history of primary and secondary education in the Colombian \\ Caribbean: The case of the Department of Atlantico
}

História recente do ensino básico e secundário no Caribe colombiano: o caso do Departamento do Atlántico

\author{
Gustavo Correa ${ }^{1}$ \\ Universidad del Atlántico, Colombia \\ Juan David Parra Heredia ${ }^{2}$ \\ Universidad del Norte, Colombia
}

Recepción: 03/12/2017

Evaluación: 30/01/2018

Aceptación: 23/02/2018

Artículo de Investigación - Revisión

https://doi.org/10.19053/01227238.9389

\section{RESUMEN}

Este artículo hace un aporte historiográfico al debate sobre los rezagos educativos en el caribe colombiano. Para ello se toma el caso del Departamento del Atlántico y se explora el proceso de formación de su institucionalidad educativa a partir de una indagación de ordenanzas departamentales publicadas en el periodo 19802014. La primera sección del artículo presenta un recuento de eventos históricos relevantes para comprender la formación del actual sistema de educación básica y media en Colombia y sirve como punto de referencia para interpretar dinámicas educativas regionales durante el periodo de estudio. La narrativa se construye a partir de la lectura de fuentes primarias, y su contraste con fuentes secundarias permite identificar los pocos incentivos con los que cuentan actores educativos importantes tales como funcionarios públicos, rectores, y docentes para impulsar más prácticas de planeación educativa en contexto. Si bien estos hallazgos deben ser verificados con otras fuentes para potenciar su poder explicativo, sientan bases analíticas para debatir los problemas educativos en el norte del país.

1 Historiador Universidad del Atlántico. Correo electrónico: correa.perseo.gustavo@gmail.com

2 Doctor en Ciencias Sociales, International Institute of Social Studies, Erasmus University Rotterdam. Correo electrónico: jparrah@ gmail.com 
Palabras clave: Revista Historia de la Educación Latinoamericana; Política educacional; Historia educación; Realismo crítico; Colombia; Región Caribe

\section{ABSTRACT}

This article makes a historiographical contribution to the debate on educational lags in the Colombian Caribbean. The analysis focusses on the case of the Department of the Atlántico and explores the process of formation of its education institutions based on the study of departmental ordinances published between 1980-2014. The first section of the article recounts relevant historical events that help to understand the configuration of Colombia's current school system and that serves as a point of reference to interpret regional educational dynamics during the period of study. The narrative is built from the reading of primary sources, and its contrast with secondary material allows to identify the few incentives that important educational actors such as public officials, principals, and teachers have to promote more educational planning practices in context. Although these findings must be verified with other sources to enhance their explanatory power, they establish analytical bases to discuss the educational problems in the north of the country.

Keywords: Journal History of Latin American Education; Education policy; history of education; Critical realism; Colombia; Caribbean Region.

\section{RESUMO}

Este artigo faz uma contribuição historiográfica ao debate sobre os atrasos educacionais no Caribe colombiano. Para isso se analisa o caso do Departamento do Atlântico e se explora o processo de formação de sua institucionalidade educativa a partir de um questionamento sobre as ordenanças departamentais publicadas no período 1980-2014. A primeira seção do artigo apresenta uma nova narrativa de eventos históricos relevantes para compreender desde a formação do atual sistema de educação básica e média na Colômbia e serve como ponto de referência para interpretar dinâmicas educacionais regionais durante o período de estudo. A narrativa se constrói a partir da leitura de fontes primárias, e seu contraste com fontes secundárias permite identificar os poucos incentivos com que contam atores educacionais importantes, tais como funcionários públicos, reitores e docentes, para impulsionar mais práticas de planejamento educativo no contexto. Se bem que estas descobertas devem ser verificadas com outras fontes para potencializar seu poder explicativo e definir bases analíticas para debater os problemas educativos no norte do país.

Palavras-chave: Revista História da Educação Latino-americana; Política educacional; Historia da educação; Realismo crítico; Colômbia; Região Caribe.

\section{INTRODUCCIÓN}

El presente estudio hace un aporte al entendimiento del contexto social e institucional en el que se enmarcan los retos de la calidad de la educación básica y media en Colombia. Un objetivo más concreto del artículo es la producción de un insumo historiográfico que contribuya al debate sobre la persistencia de desigualdades educativas en América Latina, y en particular en la región Caribe, la cual concentra rezagos históricos en materia de indicadores de cobertura, inver- 
sión, inclusión y logro escolar ${ }^{3}$. Esta es una tarea relevante y necesaria, en tanto los diagnósticos sobre el estado y los retos de la política educativa se encuentran saturados de conclusiones y recomendaciones que inciden en la reproducción de iniciativas, programas e intervenciones que han mostrado un impacto limitado en su capacidad para modificar prácticas curriculares en las instituciones educativas del país ${ }^{4}$.

Desde un plano epistemológico, el estudio de la historia es fundamental para aproximarse a las lógicas institucionales (ej. los diferentes intereses en juego) en la que se despliegan las políticas públicas. Dicho de otra manera, y bajo el entender de que el hoy es un resultado (no lineal, no determinístico) del ayer ${ }^{5}$, todo científico social interesado en entender fenómenos contemporáneos (ej. la persistencia de bajo de desempeño escolar) debe preguntarse sobre el proceso de formación de las instituciones del presente (ej. del sistema educativo), y cómo este se ve reflejado hoy en la configuración de incentivos específicos para los diferentes actores involucrados. Pese a que este último argumento puede resultar intuitivo, dicha práctica investigativa contrasta con la tendencia actualista que predomina en la investigación educativa en Colombia. Es decir, la fijación cuantitativa en el estudio de relaciones causa-efecto entre variables empíricas alusivas al sector (ej. resultados en exámenes, cualificaciones docentes) lleva a que los estudiosos del tema contemplen el entorno institucional donde operan las políticas educativas como un epifenómeno ${ }^{6}$.

Ahora bien, el abordar la historia como una fuente para estudiar los mecanismos causales del presente implica entablar una reflexión metodológica sobre como aproximarse a una versión objetiva de hechos históricos. Dicha búsqueda no deber ser entendida como un esfuerzo ingenuo (y fútil) por identificar la única versión posible del pasado ${ }^{7}$. Sin embargo, si se acepta el argumento de que existen causas reales detrás del surgimiento de fenómenos específicos (ej. la persistencia del bajo desempeño escolar), deben existir, necesariamente, mejores

3 Juan D. Parra. "El reto de la descentralización educativa: reflexiones desde la mirada de actores nacionales y subnacionales en el caso del departamento del Atlántico." Papel Político 22, no. 2 (2017): 339-367. /María Teresa Ramírez, y Juana Patricia Téllez. "La educación primaria y secundaria en Colombia en el siglo XX." En Economía Colombiana del siglo XX: un análisis cuantitativo, editado por James Robinson y Miguel Urrutia (Bogotá: Fondo de Cultura Económica. 2007). / Elias Said-Hung y Jorge Valencia. Resultados en las pruebas de Estado en la región Caribe colombiana 2009 - 2012. (Barranquilla: Observatorio de Educación del Caribe Colombiano de la Universidad del Norte, 2014) / Diana Chamorro, Mónica Borjas y Jorge Valencia. "Básica y Media." En: Situación de la educación en el caribe colombiano 2008-2011, editado por Elías Said-Hung. (Barranquilla: Observatorio de Educación del Caribe Colombiano de la Universidad del Norte, 2014).

4 Juny Montoya-Vargas. "The Field of Curriculum Studies in Colombia”. En: International Handbook of Curriculum Research $2^{\text {nd }}$ edition, editado por William Pinar. (Nueva York: Routledge, 2014).

5 Margaret Archer. Realist social theory: the morphogenetic approach. (Cambridge: Cambridge University Press, 1995) / Robert Willmott. "Structure, Agency and the Sociology of Education: Rescuing analytical dualism." British Journal of Sociology of Education 20, no. 1 (1999): 5-21.

6 Juan D. Parra. "Critical realism and school effectiveness research in Colombia: The difference it should make. "The British Journal of Sociology of Education 39, no. 1 (2018): 107-125.

7 Según nos recuerda Collier, la objetividad no debe ser entendida, o confundida, con neutralidad. Algo es objetivo en el sentido que tiene una forma y unas propiedades específicas resultado de la composición de sus partes (ej. es un objeto de). La pregunta sobre la aproximación objetiva a los hechos históricos no es una de verdades absolutas, sino de la búsqueda de condiciones específicas que hacen que un objeto social (ej. el bajo desempeño escolar), sea y se manifieste tal y como lo hace, y no de una manera diferente. La existencia de objetos sociales con propiedades específicas justifica el estudio causal de la historia, pues de lo contrario no habría nada que descubrir. Andrew Collier. In Defence of Objectivity and Other Essays on Realism, Existentialism and Politics. (Londrés y Nueva York: Routledge, 2003). 
explicaciones (o, si se quiere, mejores teorías) que otras sobre las fuerzas causales del pasado. Esta anotación es relevante en tanto existe una crítica epistemológica a las prácticas frecuentes en la investigación histórica que apunta a la poca disposición de historiadores profesionales a poner sobre la mesa sus hipótesis (falsables) de trabajo ${ }^{8}$. El riesgo que se desprende de lo anterior es que la reconstrucción de eventos históricos, y de las narrativas que los puedan conectar, queden excesivamente supeditadas a la visión subjetiva del historiador. Vicent y Wapshott resumen dicho debate en los siguientes términos:

Como resultado [de un enfoque muy relativista de análisis], los procesos estructurales se reducen a un simple epifenómeno de realidades subjetivas (...) El conocimiento de estos mecanismos a menudo requiere [de un ejercicio de] retroducción: [es decir] establecer las condiciones contextuales que dan lugar al mecanismo particular que estamos observando (...). Es posible que estos mecanismos no sean obvios o explícitos en el caso en sí, y deben elaborarse teóricamente a partir de un análisis más amplio del entorno, a menudo mediante la comparación? ${ }^{9}$.

El presente artículo recurre a fuentes secundarias para fijar un punto de referencia, o de comparación, para analizar fuentes históricas primarias -en este caso, ordenanzas- recolectadas en el Archivo Histórico de la Asamblea Departamental del Atlántico. El foco del estudio regional se centra en el periodo 19802014, trazo que permite estudiar dinámicas de la configuración y el despliegue de iniciativas educativas neoliberales ${ }^{10} \mathrm{y}$ alimentar hipótesis explicativas a la reproducción de problemas educativos en caribe colombiano. Las fuentes secundarias en este caso son publicaciones académicas de estudiosos de la historia de la educación básica y media en Colombia y que abordan el fenómeno desde finales de los años 1960 -periodo que representan un hito en la creación de una institucionalidad formal del sistema educativo nacional-. Nuevamente, el argumento no consiste en suponer que existe una única versión posible de la historia de la educación en el país, ni que la que se presente en este texto se encuentre libre de crítica. En línea con los elementos metodológicos esbozados en el párrafo anterior, la intención es contar una especie de hipótesis (ej. una narrativa general) frente a la cual leer e interpretar mandatos legislativos regionales frente a la consolidación de la institucionalidad educativa del departamento.

8 Dicho de otra manera, es común entre académicos el construir de narrativas causales sin una constelación de falsabilidad clara, situación que limita la posibilidad de verificar, cuestionar, refinar o replantear teorías sociales. Ver William Sewell. "Historical events as transformations of structures: Inventing revolution at the Bastille." Theory and Society 25, $n^{\circ} 6$ (1996): 841-881 / Heikki Patomäki. "A critical realist approach to global political economy." En: Critical Realism. The difference it makes, editado por Justin Cruickshank. (Londres and Nueva York: Routledge. 2003) /, Chris Wickham. "The Problems of Comparison." Historical Materialism 19, no. 1 (2011): 221-231.

9 Vincent, Steve, y Robert Wapshott. "Critical Realism and the Organizational Case Study: A Guide to discovering Institutional mechanisms." En Studying organizations using Critical Realism: A practical guide, editado por Paul Edwards, Joe Mahoney y Steve Vincent. (Oxford: Oxford University Press, 2014), 149-150 (Cita traducida).

10 Hernando Gómez-Buendía. Educación en América Latina y el Caribe: la Agenda del siglo XXI. (Bogotá: Programa de Naciones Unidas para el Desarrollo, 1998) / Patricia Vanegas. “The Northern Influence and Colombian Education Reform of the 1990s." En: Crisis and Hope. The Educational Hopscotch of Latin America, editado por Stephen J Ball, Gustavo E Fischman y Silvina Gvirtz. (Nueva York y Londres: Routledge, 2003). 
El documento se divide en tres secciones. La primera sección se centra en una reconstrucción con fuentes secundarias de la historia reciente de la política educativa en Colombia, la cual servirá como punto de referencia para dar el salto al estudio de dinámicas históricas regionales. La segunda sección se enfoca en la metodología de recolección de la información primaria en el archivo de la Asamblea Departamental del Atlántico y presenta unas estadísticas descriptivas de la información recolectada. La tercera sección se enfoca en la presentación de una narrativa que resume los hallazgos de la lectura de fuentes primarias y su contraste con el trazo histórico nacional. Finalmente, en las líneas de cierre del texto se utiliza la síntesis del análisis para enunciar una serie de reflexiones sobre la posible incidencia de las estructuras históricas, sociales y culturares estudiadas en la explicación de la persistencia de los rezagos educativos en subregiones del caribe colombiano.

\section{Historia reciente de la educación en Colombia}

\subsection{Las condiciones iniciales (1968-1982)}

Los acontecimientos del final de la década de 1960 representaron un antecedente importante para la consolidación del sistema educativo contemporáneo en Colombia. Según Hanson ${ }^{11}$, el reto más visible que enfrentaba el Ministerio de Educación (MEN) en ese momento era la contratación masiva e ilegal de docentes por parte de departamentos y territorios nacionales. El año 1968 se convierte en una especie de punto de inflexión en tanto el gobierno nacional, en cabeza de Carlos Lleras Restrepo y su Ministro de Educación, Octavio Arismendi Posada, toma la determinación de iniciar una fase de centralización administrativa educativa al introducir medidas de eficiencia técnica y solicitar a los gobernadores que se adhiriesen a una política de educación nacional ${ }^{12}$. A pesar de que ello se complementaba con esfuerzos más generales para incrementar el papel del estado en la economía ${ }^{13}$, semejante iniciativa se enfrentaba a la inercia de una clase dirigente que nunca antes había emprendido un proyecto de desarrollo educativo ${ }^{14}$.

La novedad de la nueva estructura institucional eran los delegados del MEN en cada gobernación, financiados por Fondos Educativos Regionales (FER) ${ }^{15}$. En

11 Mark Hanson. "Democratization and Decentralization in Colombian Education." Comparative Education Review 39, no. 1 (1995): 100-119.

12 Ibid., 107.

13 Jairo Parada. Instituciones, desarrollo y regiones. El caso de Colombia. (Barranquilla: Universidad del Norte. 2013). José Antonio Ocampo, Mauricio Avella, Jaoquín Bernal, y María Errázuriz. 2007a. "La industralización y el intervencionismo estatal (1945-1980)." En: Historia económica de Colombia: edición revisada y actualizada, editado por José Antonio Ocampo. (Bogotá: Editorial Planeta, 2007a).

14 Hillel Soifer. State Building in Latin America. (Nueva York: Cambridge University Press, 2015): 137.

15 Estos nacen en 1968 "como mecanismos de desconcentración de las funciones de tesorería (instrumentos de pago a los maestros en las regiones), destinados a atender con aportes nacionales, departamentales y municipales el sostenimiento y expansión de los servicios educativos en los planteles oficiales de educación primaria, secundaria, media y de carreras intermedias". Juan Carlos Torres y Horacio Duque. 1994. "El proceso de descentralización educativa en Colombia." Revista Colombiana de Educación 29 (1994): 7-50, 11. 
el esquema anterior las Secretarías de Educación (SEC) territoriales se entendían directamente con el gobernador y, por tanto, el MEN tenía acceso casi nulo a lo que sucedía en los colegios ${ }^{16}$. Esta nueva configuración administrativa representaba el crear una conexión directa entre el territorio y el poder ejecutivo central. Y pese a la resistencia inicial de algunos gobernadores para permitir a los delegados ejercer tareas de inspección, su poder empieza a consolidarse en la segunda mitad de los años 70. Ello se explica, en parte, por una nueva cultura de cambio que representó la renovación de gobernadores y miembros de secretarías de educación de $1973^{17}$. No obstante, y a pesar de logros en materia de organización financiera educativa, pronto llegaría la politización de esta figura, lo cual paradójicamente, mejora sus relaciones con las clases dirigentes en el territorio ${ }^{18}$.

La necesidad fiscal de contar con un sector educativo mejor organizado implicará un choque entre la lógica de centralización administrativa y las demandas por descentralización política en los años 80. Era un momento de una fuerte presión en la demanda por cupos escolares. Los datos que reporta Helg indican un crecimiento de $820 \%$ en la matrícula en educación secundaria entre 1958 y $1980^{19}$. La afluencia creciente de poblaciones menos privilegiadas a un sistema escolar dominado por el sector privado y la iglesia daría como resultado la apertura de nuevos colegios oficiales -con una creciente participación de créditos extranjeros-. Sin embargo, la baja integración entre estudiantes de diferentes niveles socioeconómicos reproduciría los privilegios de clase presentes antes del Frente Nacional ${ }^{20}$. Esta situación, según Helg, contribuye al desprestigio de la oferta educativa pública y, de paso, del gremio del magisterio. En medio de tal dinámica, la Federación Colombiana de Educadores (Fecode) fortalecía su reivindicación sindical ${ }^{21}$, la cual tuvo nuevo impulso con la expedición del estatuto

16 Mark Hanson. "Democratization and Decentralization in Colombian Education." Comparative Education Review 39, no. 1 (1995): $100-119$.

17 De acuerdo con Hanson, en el periodo inicial de los FER todos los involucrados -los delgados, los secretaros de educación, los gobernadores, y personal del ministerio carecían de información precisa sobre lo que tenía que hacerse y cómo. Ello genero conflictos y enfrentamientos. En 1973, sin embargo, la nueva generación de gobernadores, secretarios de educación fue menos propensa a sostener las viejas prácticas.

18 Aline Helg. “La educación en Colombia, 1958-1980." En: Nueva historia de Colombia, editado por Álvaro Tirado Mejía. (Bogotá: Planeta Colombiana Editorial, 1986).

19 Ibid.

20 El caso de los Institutos Nacionales de Enseñanza Media Diversificada (INEM) es ilustrativo frente a esta dinámica: "Los INEM fueron establecidos en 1969, concretando la antigua esperanza de los responsables educativos de crear una alternativa técnica real al bachillerato clásico. Los INEM debían recibir originalmente a alumnos de distintos grupos sociales y fortalecer las relaciones inter-clase. Sin embargo, construidos en barrios populares (...) y orientados a carreras técnicas (...) nunca atrajeron a alumnos de las clases superior y media alta (...) Los INEM fueron concebidos con la asistencia de técnicos de Estados Unidos. El Banco Mundial financió diez de los veintinueve millones de dólares que eran el costo inicial de construcción de los diecinueve institutos previstos. Los Estados Unidos proporcionaron, también, ayuda técnica para la formación de los administradores y los profesores de los establecimientos". Aline Helg. "La educación en Colombia, 1958-1980." En: Nueva historia de Colombia, editado por Álvaro Tirado Mejía. (Bogotá: Planeta Colombiana Editorial, 1986), 145.

21 Según Ramírez y Téllez "La expansión de la educación y el aumento en el número de docentes de los mismos permitieron que las asociaciones de educadores cobraran importancia en la década de los sesenta (...). La Federación Colombiana de Educadores (Fecode) se crea oficialmente en 1962 sobre la base de sindicatos departamentales. Durante los sesenta, el magisterio gracias a numerosas huelgas que afectaron el desarrollo de la educación obtuvo alzas en salarios y mejoras en capacitación”. María Teresa Ramírez, y Juana Patricia Téllez. "La educación primaria y secundaria en Colombia en el siglo XX." En Economía Colombiana del siglo XX: un análisis cuantitativo, editado por James Robinson y Miguel Urrutia (Bogotá: Fondo de Cultura Económica. 2007), 502. 
docente (Decreto 2277 de 1979) y la unión, en representatividad política, de docentes de niveles de educación primaria y secundaria.

\title{
1.2 Los cimientos de la descentralización educativa (1983-2000)
}

La década del 80 inicia una fase de reformas para darle mayor autonomía política y administrativa a los entes territoriales. El siguiente fragmento, de Ocampo et al., ilustra el cambio de tendencia en el modelo de prestación de servicios estatales y las dificultades institucionales que surgen en medio de dicha transición:

\begin{abstract}
El modelo de descentralización que surgió en Colombia ha sido, a la postre, un híbrido entre uno en el cual los gobiernos territoriales son esencialmente ejecutores de políticas deseadas a nivel central (de "agentelprincipal", de acuerdo a la terminología en boga), que prevaleció hasta los años ochenta, y uno de elección pública local, en el cual los entes locales gozan de autonomía real en la definición de sus políticas, y son responsables directamente ante la ciudadanía por los servicios que prestan. Este modelo híbrido se ha caracterizado por la dificultad para determinar en forma precisa las responsabilidades de los distintos niveles de gobierno y para coordinar las distintas fuentes de financiamiento. ${ }^{22}{ }^{23}$
\end{abstract}

La transformación del modelo (al menos en un sentido formal) del Estado tiene uno de sus primeros antecedentes en la expedición de Ley 14 de 1983, la cual otorgaría independencia a los municipios sobre impuestos a la renta, el catastro y el predial ${ }^{24}$. Durante la presidencia de Virgilio Barco (1986-1990) se establece del Estatuto Básico de la Administración Municipal (Ley 11 de 1986) y se hace efectiva la primera elección popular de alcaldes y gobernadores. A nivel educativo, la Ley 12 de 1986 incrementa las transferencias del gobierno central a los municipios y les entrega la responsabilidad a los gobiernos locales frente al desarrollo y sostenimiento de la infraestructura educativa, tarea que venía siendo ejecutada por el Instituto Colombiano de Construcciones Escolares. Dos años después, la Ley 24 de 1988 da paso a una restructuración del MEN para afrontar retos de la descentralización y entrega a los gobiernos locales la potestad para

22 José Antonio Ocampo, Carmen Astrid Romero y María Ángela Parra. 2007. "La búsqueda, larga e inconclusa, de un nuevo modelo (1981-2006)." En Historia económica de Colombia: edición revisada y actualizada, editado por José Antonio Ocampo. (Bogotá: Editorial Planeta. 2007), 396.

23 De la Calle hace un comentario similar cuando afirma que "El arranque de la Constituyente fue bastante municipalista (...) De algún modo, esa situación crítica actual de los departamentos, que incluso desconocen su propia identidad y cuyo papel institucional es todavía confuso, obedeció a que al final del periodo constituyente hubo que rescatar viejas normas de la Carta de 1886, y salió de allí un departamento contrahecho, cuyas funciones no son claras y sin un sistema tributario". Humberto De la Calle. "Las ilusiones fallidas de la descentralización." En Memorias del Seminario 20 años de la descentralización en Colombia: presente y futuro, editado por Darío Restrepo. (Bogotá: Red de Iniciativas para la Gobernabilidad, la Democracia y el Desarrollo Territorial - RINDE. 2007)., 13.

24 Francisco Gutierrez. "Instituciones y territorio. La descentralización en Colombia." En 25 años de la descentralización en Colombia. (Bogotá: Konrad Adenauer Stifttung. 2010). 
nombrar y administrar el personal docente, aunque el manejo del tema salarial queda subordinado al nivel nacional ${ }^{25}$.

El modelo de descentralización administrativa en educación es refrendado en el marco de la Constitución de 1991 a partir de la nueva definición de competencias y funciones de las entidades territoriales y la distribución del situado fiscal para la prestación de servicios educativos (Ley 60 de 1993). Un año después entra en vigencia la Ley General de Educación (Ley 115 de 1994) que profundiza la cesión de derechos de participación de los departamentos en la administración de los $\mathrm{FER}^{26}$ y da paso a la materialización de principios de autonomía en la organización administrativa y pedagógica de instituciones educativas ${ }^{27}$. Dicha lógica político-administrativa se ve entrelazada con tendencias internacionales -como la declaración de Naciones Unidas sobre los derechos de los niños- que consagran la educación como un derecho fundamental y que demanda concertaciones entre actores civiles y gubernamentales. Sin embargo, señala Cajiao, Fecode y el gobierno terminan imponiendo una agenda de negociación bilateral, en un "proceso [que] arrancó desconociendo el principio que postula que la educación es un asunto de todos" ${ }^{28}$ y que termina privilegiando el debate regulatorio.

Las políticas implementadas durante los años 90 siguen haciendo avances hacia garantizar la cobertura escolar y la resolución de temas financieros del sector. En año 1996 se crea un Fondo Educativo de Compensación (FEC) con el objetivo "intentar cerrar la brecha entre los recursos del sistema y el pago de maestros" ${ }^{29}$ En cuanto a la denominada calidad educativa; se institucionaliza, desde 1991, un mecanismo para su medición por medio de la realización de pruebas estandarizadas en los grados quinto, séptimo y noveno. El uso de estos indicadores muestra una caída en el logro escolar durante la década de los noventa, que, a juicio de investigadoras del Banco de la República, se explica por las tasas de fracaso y repetición escolar en niveles de primaria y secundaria. ${ }^{30}$ Esta década finalizará con una profunda crisis económica, la cual impactaría en la reducción del recaudo tributario y de las transferencias del Estado central a los territorios, generando incertidumbre sobre la disponibilidad de los recursos destinados a servicios sociales de salud y educación. ${ }^{31}$

25 María Teresa Ramírez, y Juana Patricia Téllez. "La educación primaria y secundaria en Colombia en el siglo XX." En Economía Colombiana del siglo XX: un análisis cuantitativo, editado por James Robinson y Miguel Urrutia (Bogotá: Fondo de Cultura Económica. 2007).

26 Dicho proceso tenía ya un antecedente en la Ley 29 de 1989, la cual había trasladado tareas de coordinación de los FER a las alcaldías locales. Gustavo Bell y Alexandra García. Costos y Beneficios de dos modelos de ordenamiento territorial para el Caribe colombiano. (Barranquilla: Dirección de Investigaciones y Proyectos del Centro de Estudios Regionales (CERES). Universidad del Norte. 1999).

27 María Teresa Ramírez, y Juana Patricia Téllez. “La educación primaria y secundaria en Colombia en el siglo XX.” En Economía Colombiana del siglo XX: un análisis cuantitativo, editado por James Robinson y Miguel Urrutia (Bogotá: Fondo de Cultura Económica. 2007).

28 Francisco Cajiao. “La concertación de la educación en Colombia." Revista Iberoamericana de Educación no. 34 (2004): 31-47, 41.

29 Felipe Barrera-Osorio. "La política de educación en Colombia 1957-2004." Coyuntura Económica XXXV, 2 (2005): 307-314, 309.

30 María Teresa Ramírez, y Juana Patricia Téllez. "La educación primaria y secundaria en Colombia en el siglo XX.” En Economía Colombiana del siglo XX: un análisis cuantitativo, editado por James Robinson y Miguel Urrutia (Bogotá: Fondo de Cultura Económica, 2007).

31 Jaime Bonet, Gerson Pérez y Jhorland Ayala. Contexto histórico y evolución del SGP en Colombia. (Cartagena: Documentos de Trabajo Sobre Economía Regional. Banco de la República. 2014). 
En palabras de Gómez-Buendía, estas transformaciones en políticas educativas "tienen un sabor de clara estirpe liberal: eficiencia, desregulación, descentralización, 'focalización' y 'participación'" 32. Pese a ello, muchos de los retos educativos experimentados a lo largo de las últimas décadas tenían vigencia al finalizar el siglo. Las brechas regionales aún eran significadas en indicadores como la relación alumnos matriculados sobre la población en diferentes regiones del país ${ }^{33}$. Todo ello incidirá en una nueva transición de prioridades hacia temas como la dotación de materiales en colegios y el interés desde las políticas públicas en torno a debates sobre aproximaciones pedagógicas al aprendizaje. Entre las propuestas de un nuevo plan de desarrollo (1998-2002) se plantean estrategias para hacer más eficiente la administración docente y el esquema de financiación del sector educativo, todo cobijado por una estructura institucional que migra de subsidiar la oferta y empieza a incentivar la demanda ${ }^{34} 35$.

\subsection{Rescatando los criterios de eficiencia en el gasto (2001-2014)}

Parafraseando a un antiguo Secretario de Educación de Bogotá, a pesar de los posibles avances que se dieron a finales de la década de los 90 en materia de procesos de concertación para definir planes educativos de largo plazo ${ }^{36}$, la transición hacia el nuevo milenio estuvo marcada por el retorno al énfasis en el "desarrollo de mecanismos de control y de estrategias de eficiencia, dejando de lado las grandes discusiones sobre el sentido del Sistema Educativo" ${ }^{37}$. Una de las respuestas a los retos económicos heredada de años anteriores es la expedición del Acto Legislativo 1 con el cual se crea el Sistema General de Participaciones (SGP) "que organizó en una sola bolsa los recursos educativos y estableció las transferencias bajo un criterio de responsabilidad fiscal por parte de los municipios" y en el cual, estos "son certificados por medio de índices de endeudamiento y solvencia" ${ }^{38}$. Este nuevo entorno normativo dará también nacimiento al Decreto 1278 de 2002, o al nuevo estatuto de profesionalización docente, por medio del cual se introducen parámetros de ingreso, ascenso, permanencia y retiro del

32 Hernando Gómez-Buendía. Educación en América Latina y el Caribe: la Agenda del siglo XXI. (Bogotá: Programa de Naciones Unidas para el Desarrollo, 1998), 125.

33 María Teresa Ramírez, y Juana Patricia Téllez. "La educación primaria y secundaria en Colombia en el siglo XX." En Economía Colombiana del siglo XX: un análisis cuantitativo, editado por James Robinson y Miguel Urrutia (Bogotá: Fondo de Cultura Económica. 2007).

34 Ana María Iregui, Ligia Melo y Jorge Ramos. "La educación en Colombia: análisis del marco normativo." Revista de Economía del Rosario, 9, no. 2 (2006): 175-238.

35 Dichos cambios se encuentran enmarcados dentro de tendencias internacionales sobre reformas educativas bajo el liderazgo de instituciones como el Banco Mundial. Karen Mundy y Antoni Verger. "The World Bank and the global governance of education in a changing world order." International Journal of Educational Development 40, Enero (2015): 9-18.

36 Cajiao comenta sobre el amplio proceso de concertación en torno al plan Decenal de Educación 1996-2005, el cual contó con la participación de servidores públicos, universidades, medios de comunicación y organizaciones civiles en cerca de 150 mesas de trabajo y más de 300 foros en todo el país. Sin embargo, aclara, hubo una ausencia marcada de representantes académicos, fuerzas sindicales y voceros de sectores productivos. Ver Francisco Cajiao. "La concertación de la educación en Colombia." Revista Iberoamericana de Educación no. 34 (2004): 31-47.

37 Ibid., 46

38 Felipe Barrera-Osorio. "La política de educación en Colombia 1957-2004." Coyuntura Económica XXXV, 2 (2005): 307-314, 309. 
servicio, al tiempo que se establece un nuevo esquema de escalafón salarial basado en el desempeño profesional y no solo al tiempo de servicio acumulado ${ }^{39} 40$. La llamada calidad de docente se convertirá en la gran protagonista del debate sobre la educación básica y media, en particular a partir de la publicación de una serie de informes internacionales tras los cuales se institucionaliza la consigna que dicta que la calidad del sistema educativo no puede superar la calidad de sus profesores ${ }^{41}$. El surgimiento de visiones de buen gobierno de mediados de los años 2000 exaltaba, por tanto, la importancia de "hacer a los docentes responsables por su desempeño" ${ }^{42}$.

Los esfuerzos administrativos mencionados se ven reforzados por el espíritu descentralizador y, sostienen Ocampo et al., ${ }^{43}$ la exaltación de argumentos propios de la escuela de la elección pública, en defensa de autonomía territorial. Lo anterior da sustento a los esfuerzos de principios de siglo de modernización de secretarias de educación territoriales que, en línea con las recomendaciones del Banco Mundial, tenían como objetivo específico el incrementar las capacidades locales, aclarar los papeles y las responsabilidades en la provisión de servicios educativos, mejorar los sistemas de tecnología de información, y crear estándares y protocoles para asegurar que los recursos fuesen utilizados de una manera eficiente y equitativa ${ }^{44}$. Ejemplos de ello son la publicación de documentos del Consejo Nacional de Política Económica y Social (CONPES) en 2005 y 2011 para hacer ajustes al SGP encaminados a profundizar sus criterios de eficiencia, así como la expedición del Decreto 1055 de 2011 donde se establecen esquemas de incentivos monetarios a rectores de instituciones educativas que muestren resultados sobresalientes en las pruebas de Estado. ${ }^{45}$

Finalmente, en cuanto a la migración hacia un enfoque de estímulos a la demanda, Barrera-Osorio et al. ${ }^{46}$ presentan un resumen de iniciativas de gran escala de gobiernos recientes y encaminadas a afrontar retos pendientes en materia de cobertura y calidad (medida a partir del desempeño escolar). Entre ellas, los programas de transferencias condicionadas al cumplimiento de requisitos en salud y educación (ej. Familias en Acción, el programa distrital de Bogotá de Subsidios Condicionados a la Asistencia Escolar), el programa de gratuidad es-

39 Ana María Iregui, Ligia Melo y Jorge Ramos. "La educación en Colombia: análisis del marco normativo." Revista de Economía del Rosario, 9, $\mathrm{n}^{\circ} 2$ (2006): 175-238.

40 El mecanismo de años en el servicio definía los ascensos salariales en el Decreto 2277 de 1979.

41 Juan D. Parra. “The Paradigm of Critical Realism and Involving Educators in Policy Debates." GIST Education and Learning Journal, no. 10 (2015): 149-171.

42 Ana María Iregui, Ligia Melo y Jorge Ramos. "La educación en Colombia: análisis del marco normativo." Revista de Economía del Rosario, 9, $\mathrm{n}^{\circ} 2$ (2006): 175-238, 181.

43 José Antonio Ocampo, Carmen Astrid Romero y María Ángela Parra. 2007. La búsqueda, larga e inconclusa, de un nuevo modelo (1981-2006). En Historia económica de Colombia: edición revisada y actualizada, editado por José Antonio Ocampo. (Bogotá: Editorial Planeta, 2007).

44 Ben Meade y Alec Ian Gershberg. "Making education reform work for the poor: accountability and decentralization in Latin America." Journal of Education Policy 23, no. 8 (2008): 299-322.

45 Barrera-Osorio, Felipe, Darío Maldonado y Catherine Rodriguez. "Calidad de la educación básica y media en Colombia: diagnóstico y propuestas." En: Equidad y movilidad social. Diagnósticos y propuestas para la transformación de la sociedad colombiana, editado por Armando Montenegro y Marcela Mélendez. (Bogotá: Universidad de los Andes, 2014).

46 Ibíd. 239-330. 
colar para reducir barreras económicas de acceso al sistema entre familias de menores recursos, el Proyecto de Educación Rural (PER) para aumentar la asistencia escolar en zonas campesinas y el programa Computadores para Educar para enfrentar componentes pedagógicos y de aprendizaje. Algunas de estas iniciativas han sido cofinanciadas por el Banco Mundial, entidad que desde mediados de la década anterior había anunciado que revitalizaría su enfoque en el alivio de la pobreza, y reestructuraría sus prácticas para hacerlas más centradas en el cliente ${ }^{47} 48$.

\section{Apuntes metodológicos para la consulta de fuentes primarias}

Antes de entrar en el análisis de fuentes primarias, resulta relevante traer a colación otros referentes de la literatura secundaria para delinear aspectos específicos del contexto del estudio. De acuerdo con la investigación histórica de Parada $^{49}$ sobre el desarrollo institucional de tres grandes regiones de Colombia, la costa caribe representa un caso de instituciones políticas y sociales débiles, frente a otros territorios del país. Ello se explica, en parte, por una configuración histórica específica, legado de las instituciones coloniales, y que incidieron en un desarraigo de esta región frente a dinámicas de la vida nacional ${ }^{50}$.

Lo anterior permite inferir que existía un interés limitado por parte de las élites regionales en consolidar un sistema educativo nacional ${ }^{51}$. Habría que mencionar, por ejemplo, la tendencia histórica del caribe hacia una baja participación industrial en el producto interno bruto regional, en comparación con otras zonas del país ${ }^{52}$. Este fenómeno no solo se entrelaza con un ritmo de crecimiento de la región por debajo del promedio nacional -0.94\% vs 2\%, entre 1950 y 1990, respectivamente ${ }^{53}$-, sino que contrasta con esfuerzos que se hacían desde Bogotá orientados a generar una educación media técnica enfocada en labores industriales. Ello se manifiesta, a su vez, en los diagnósticos más recientes sobre la

47 Karen Mundy y Antoni Verger. "The World Bank and the global governance of education in a changing world order." International Journal of Educational Development 40, Enero (2015): 9-18, 13.

48 Este es un dato de contexto relevante, en tanto, entre 1996 y 2012 Colombia pasará a ser uno de los mayores receptores de créditos de esta institución en el planeta. En ibid.

49 Jairo Parada. Instituciones, desarrollo y regiones. El caso de Colombia. (Barranquilla: Universidad del Norte, 2013).

50 Soifer presenta a Colombia como un país de regiones que hacía mitad del siglo XX contaba con una corriente liberal anti estatista que ayuda a entender la debilidad de su estado central hoy. Hillel Soifer. State Building in Latin America. (Nueva York: Cambridge University Press, 2015). Para un diagnóstico similar ver Marco Palacios y Frank Safford. Colombia: Fragmented Land, Divided Society. (Nueva York: Oxford University Press, 2002).

51 Según Ramírez y Téllez mientras que en 1916 Santander y Norte de Santander tenían cerca de 40 alumnos por maestro en educación primaria, Boyacá, Atlántico y Nariño tenían alrededor de 70. La misma tendencia se observa a finales de 1920. Indicadores como la relación alumnos matriculados en primaria frente al tamaño población en la mitad del siglo XX relevaban también un rezago educativo entre departamentos como el Atlántico y Bolívar (menos de 6\%) y casos como el de Antioquia (10.5\%), Huila (9\%), Valle, Boyacá y Nariño (7.5\%). María Teresa Ramírez, y Juana Patricia Téllez. "La educación primaria y secundaria en Colombia en el siglo XX." En Economía Colombiana del siglo XX: un análisis cuantitativo, editado por James Robinson y Miguel Urrutia (Bogotá: Fondo de Cultura Económica. 2007).

52 Jairo Parada. "Desarrollo regional y desarrollo institucional en la costa atlántica." Ensayos de Economía 2, n 1 (1991): 29-36 / Adolfo Meisel. "Albert O. Hirschman y los desequilibrios económicos regionales: de la economía a la política, pasando por la antropología y la historia." Desarrollo y Sociedad 62 (2008): 203-223 / Jaime Bonet y Adolfo Meisel. "Regional economic disparities in Colombia." Journal of Regional Research 14 (2009): 61-80

53 Jairo Parada. Instituciones, desarrollo y regiones. El caso de Colombia. (Barranquilla: Universidad del Norte. 2013). 
educación nacional, y la manifestación de brechas regionales que persisten en el tiempo. Así, por ejemplo, según un ejercicio publicado en 2014:

Los resultados de las Pruebas [de Estado] de las instituciones educativas de la Región Caribe fueron más bajos que la media nacional. Lo anterior se evidenció en todas las pruebas analizadas (...) el camino hacia la mejora en los resultados de aprendizaje viene de la mano con programas de intervención para la cualificación de los procesos pedagógicos y la revisión y ajuste de la estructura curricular de las instituciones educativas ${ }^{54}$

En cuanto a la generación de capacidades locales para el desarrollo de políticas educativas que se ajusten a contextos y necesidades específicas, estudios como el de Henríquez ${ }^{55}$ resaltarían el hecho que:

\begin{abstract}
[la] región Caribe poco ha avanzado hacia la creación de programas que fortalezcan tanto la formación de los agentes, como la adecuada formulación e implementación de políticas públicas en educación desde cada entidad territorial, lo cual agrava la situación en tanto no se está formando suficientemente a la población para generar masa crítica para el tratamiento de los problemas y necesidades de la población con un enfoque de desarrollo que tenga en cuenta las potencialidades de los individuos ${ }^{56}$.
\end{abstract}

Dichos antecedentes dan contexto a la lectura de fuentes primarias para reconstruir los eventos de la historia reciente de la educación en el Departamento del Atlántico, el cual inicia un proceso formal de descentralización educativa a finales de los años 80 y que no necesariamente representa el mismo proceso que se dio en que otras regiones del país ${ }^{57}$. La fuente de información primaria de este artículo fue recolectada en el Archivo Histórico de la Asamblea Departamental del Atlántico. Según el artículo 72 del Decreto 1222 de 1986, las ordenanzas son "[1]os actos de las asambleas departamentales destinados a dictar disposiciones para el arreglo de alguno de los asuntos que son de su incumbencia". Como tal, al menos en su sentido normativo, los contenidos de estos documentos son reflejo del máximo ejercicio de deliberación democrática en el nivel territorial ${ }^{58}$. El gráfico 1 muestra la distribución por año de las 209 ordenanzas consultadas entre el periodo 1980 y 2014. La recolección fue hecha por un historiador profesional y con experiencia previa en este tipo de consultas ${ }^{59}$.

54 Elias Said-Hung y Jorge Valencia. Resultados en las pruebas de Estado en la región Caribe colombiana 2009 - 2012. (Barranquilla: Observatorio de Educación del Caribe Colombiano (OECC) de la Universidad del Norte. 2014), 39-40.

55 Hermes de Jesús Henríquez. "Politicas públicas en educación y desarrollo en la Región Caribe." Revista de Economía del Caribe 12 (2013): 217-246.

56 Ibid., 239-241

57 Gustavo Bell y Alexandra García. Costos y Beneficios de dos modelos de ordenamiento territorial para el Caribe colombiano. (Barranquilla: Dirección de Investigaciones y Proyectos del Centro de Estudios Regionales (CERES). Universidad del Norte. 1999) / Orlando Fals-Borda y Miguel Borja. “Guía práctica del Ordenamiento Territorial en Colombia." Revista Foro 36 (1999): 74-92.

58 DNP y ESAP. Las Asambleas Departamentales y su papel en la gestión pública para el desarrollo. (Bogotá: Guías para la gestión pública territorial. Departamento Nacional de Planeación, 2011).

59 Las ordenanzas consultadas hacen referencia en sus enunciados o en su contenido a temas educativos en general (independiente del nivel de educación o la naturaleza pública, privada de la misma). Estas fueron fotografiadas y se encuentran consolidadas en un archivo electrónico. 
Gráfico 1. Número de ordenanzas consultadas por año

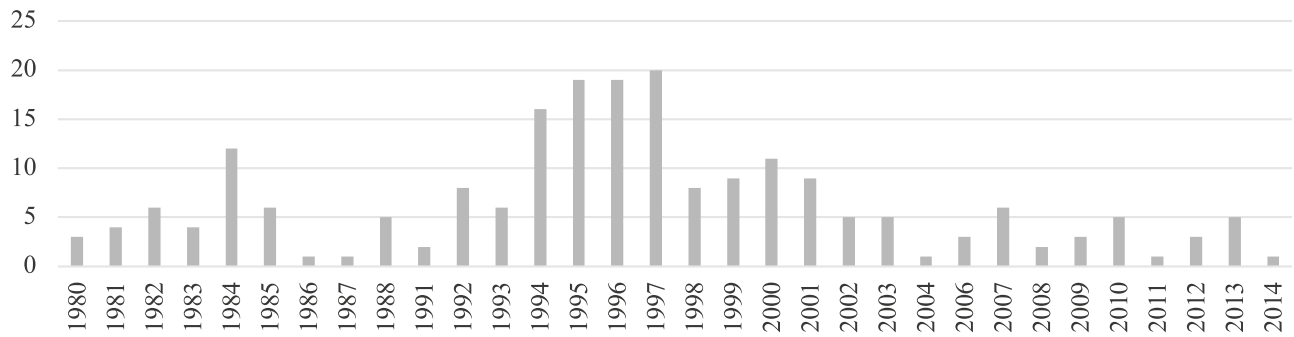

Las ordenanzas son documentos escritos y archivados en físico (con excepción de ordenanzas entre 2011-2014 que fueron recolectadas en formato electrónico), y cuentan, en su mayoría, con cerca de diez páginas (cada una). El tamaño varía según el asunto de las ordenanzas (por ejemplo, las de presupuesto pueden ser más extensas). En algunos casos estas incluyen anexos de antecedentes históricos, información sobre el marco jurídico al que responden y borradores sobre proyectos de ordenanzas. En cuanto al estado del archivo, la organización de los documentos dista de ser idónea. Al final, no es posible tener certeza de que se revisaran todas ordenanzas del periodo, en tanto no todos los libros y carpetas donde se guardan las ordenanzas se encontraban dentro de la bodega física de la asamblea. El Anexo contiene más detalles sobre estas observaciones y las implicaciones y acciones que fueron tomadas por el equipo investigador al respecto.

Gráfico 2. Categorías mencionadas en ordenanzas

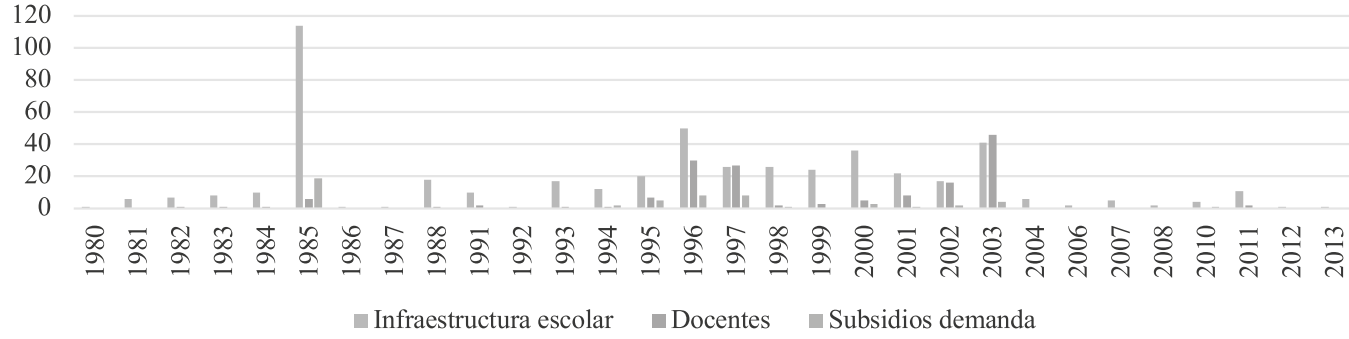

Nota: En una ordenanza se puede mencionar más de una categoría, y por tanto el número de categorías supera el número de ordenanzas. El caso de infraestructura en 1985, más que reflejar gran actividad en este rubro, se explica por qué las ordenanzas de ese año depuran la información según instituciones educativas (el caso contrario es el de ordenanzas que agrupan información en categorías generales: por ejemplo, infraestructura en colegios del departamento).

Una vez finalizada la recolección el equipo de investigación procedió a generar una metodología de categorización. Luego de algunos intentos por clasificar 
la información de diferentes formatos se tomó la decisión de crear categorías (muy) generales, y presentar los resultados en forma de una narrativa, en tanto las discrepancias en formato y contenido entre años dificultan la posibilidad de estandarizar información sin hacer supuestos arbitrarios. Los gráficos 2 y 3 fueron elaborados durante el proceso de lectura de las ordenanzas con el objetivo de registrar tendencias generales que sean útiles para interpretar hallazgos y resultados. Sería importante mencionar, sin embargo, la manera en que dichas tendencias denotan vacíos en información. En particular el gráfico 3, construido con base en ordenanzas de presupuesto y complementada con datos de otros estudios o instituciones para examinar una tendencia nacional, ejemplifica lo difícil que es trazar información de este tipo en el tiempo.

Gráfico 3. Apropiaciones de rubros educativos. \% del presupuesto total

80

60

40

20

0

サ MinHacienda (Nacional) $\quad$ Ramírez y Téllez (2007) (Nacional) $\quad$ Departamento Atlántico

Fuente: Cálculo de los autores a partir de ordenanzas departamentales y documentos publicados en la página de la gobernación del Atlántico. Los datos Nacionales provienen del Ministerio de Hacienda y Crédito Público y la base de datos de Ramírez \& Téllez ${ }^{60}$.

\section{Hacia una reconstrucción de la historia reciente de la educación en el de- partamento del Atlántico}

Esta sección del documento presenta, a manera de narrativa, los hallazgos del análisis de las ordenanzas consultadas. Los resultados se agrupan por décadas (1980-1989, 1990-1999, 2000-2014) y no por los periodos utilizados en la discusión de la política educativa nacional. Aun cuando lo ideal podría ser utilizar los mismos cortes de tiempo, este es un ejercicio exploratorio hacia la construcción de una historia de la educación en la región, tarea que para ser completada requeriría del análisis de otras fuentes de información (ej. entrevistas con informantes clave, consulta de fuentes periodísticas). Dentro de dicha lógica, se con-

60 María Teresa Ramírez, y Juana Patricia Téllez. "La educación primaria y secundaria en Colombia en el siglo XX." En Economía Colombiana del siglo XX: un análisis cuantitativo, editado por James Robinson y Miguel Urrutia (Bogotá: Fondo de Cultura Económica, 2007). 
sideró que trabajar con cortes (casi) homogéneos de información es un esquema práctico para hacer una primera pasada sistemática de la información ${ }^{61}$.

\subsection{Periodo 1980-1989}

Un primer referente de este periodo es la Ordenanza 8 de noviembre de 1980 que da nacimiento a los Distritos Educativos y Núcleos Escolares en aras de cumplir con el requerimiento para la constitución y el financiamiento del Programa Mapa Educativo. La Ordenanza 11 de diciembre de ese mismo año crea el Fondo Espacial para la Construcción y Adecuación de Escuelas y Colegios Departamentales y en su artículo primero le otorga autonomía administrativa, patrimonio propio y personería jurídica. El Gobernador del Atlántico es designado encargado de reglamentar el funcionamiento del Fondo, tarea que incluye la escogencia del personal administrativo y también el establecimiento de funciones en la corporación.

La inversión infraestructural en el sector educativo del departamento tiene un impulso notable a partir de 1981. Así, por ejemplo, en la Ordenanza 13 se asignan partidas al Instituto Experimental y a la creación de instituciones educativas como el Colegio Cooperativo Bachillerato Nocturno Veinte de Julio, el Colegio Bachillerato la Misericordia en Soledad -el cual parece ser de los primeros proyectos a ejecutarse por fuera de la ciudad capital del departamento- y se autoriza la construcción del Centro Educativo del Bienestar Popular ubicado en el barrio El Pueblo de Barranquilla. A su vez la Ordenanza 15 de 1984 ordena la entrega de partidas adeudadas por parte del Estado (de 35,9 millones de pesos ${ }^{62}$ ) a las Escuelas Gratuitas de San Roque, al tiempo que se les asigne un rubro adicional de 9,6 millones. La tendencia frente al gasto de este tipo muestra un pico (en términos de partidas mencionadas en la normatividad) en 1985 (Gráfico 2), y coincide con iniciativas de la descentralización nacional materializadas en la Ley 4 de 1983.

Esta década también permite identificar iniciativas orientadas a la definición de competencias y responsabilidades de actores del sector educativo. En tal sentido, la Ordenanza 19 de 1983 le confiere a la Asociación de Educadores del Atlántico (Adea) la facultad para administrar el Fondo de Vivienda del Magisterio -poniendo un límite superior de 2,8 millones de pesos al valor de proyectos que puedan ser ejecutados sin previa participación de la asamblea- pero no para modificar autónomamente su estatuto de funcionamiento. A mediados de la misma década empieza a hacerse énfasis en asuntos relacionados a la gestión de recursos, la conformación de entidades administrativa del sector educativo en el departamento y en la delineación de planes y programas. Dentro del contexto

61 Aun así, estas fechas guardan lógica con tres momentos que representan diferentes etapas en el proceso de desarrollo educativo: i) la preparación para la descentralización, ii) la descentralización política y iii) la era de la eficiencia y de la centralización (relativa) de la planeación educativa, respectivamente. Ver Leonardo Villar y otros. Sistema General de Participaciones y su vínculo con las politicas e incentivos dirigidos a la excelencia docente y el mejoramiento continuo de la calidad de la educación. (Bogotá: Fundación para la Educación Superior y el Desarrollo, 2016).

62 Todas las cifras monetarias se expresan en pesos de 2016. 
de los cambios institucionales de 1986 frente a la elegibilidad de líderes políticos regionales, la Ordenanza 1 de octubre de ese año legisla sobre la asignación de autonomía administrativa a los jefes de entidades territoriales, facultando al Gobernador del Atlántico para realizar reformas administrativas en las juntas directivas de entidades descentralizadas, con excepción de la Universidad del Atlántico.

Si bien el trazado normativo permite también entrever la generación de un esquema de incentivos a la demanda - a través la entrega de la insignia Julio Enrique Blanco de la Rosa a estudiantes que muestren desempeños sobresalientes en las pruebas de Estado (Ordenanza 23 de 1988)-, el énfasis general de esta época gira en torno a la conformación de estructuras institucionales. Cabría mencionar, a nivel más global, la reestructuración del MEN por medio de la Ley 24 de 1988, y luego de ello la expedición de la Ley 29 de 1989 que le entrega de manera facultades a las alcaldías para encargarse de hacer modificaciones a la nominación y administración de la planta docente ${ }^{63}$. En este contexto, la descentralización educativa se consolidaría con el inicio de la década de los años noventa.

\subsection{Periodo 1990-1999}

El Decreto 1246 de 1990 dividió cargas administrativas y financieras del Sistema Nacional de Educación entre entes territoriales y la Nación, lo cual implicó para el Departamento del Atlántico la necesidad de hacer mayores esfuerzos fiscales ${ }^{64}$. En tal medida, se presentan actos legislativos orientados a solventar necesidades financieras regionales. Es el caso de la Ordenanza 40 de 1993, a través de la cual se suscribe un convenio con el MEN para la cofinanciación de nuevas plazas docentes en educación secundaria - y se entregan facultades al Gobernador Departamental para que habilite créditos y contracréditos con ese fin (Ordenanza 16 de 1992).

En los primeros años de esta década se legisla también para dar fortaleza institucional a una de las principales universidades públicas de la región. Así, por ejemplo, la Ordenanza número 10 de 1992 fortalece los programas de formación académica de la Universidad del Atlántico (con sede principal en Barranquilla) y se ponen a disposición nuevas sedes administrativas y docentes en los municipios del departamento para la enseñanza en los niveles de pregrado y posgrado. Se hace énfasis en este acto legislativo porque se le concede a esta última institución el papel de ente consultor de la asamblea departamental para todos los asuntos de interés público (Ordenanza 20 de 1992). Aunque no hay mayor exposición de motivos (no, al menos, en el archivo en físico disponible para la consulta), puede inferirse que con ello se le da a la Universidad del Atlántico un papel estratégico en la definición de políticas educativas de la región ${ }^{65}$.

\footnotetext{
63 Gustavo Bell y Alexandra García. Costos y Beneficios de dos modelos de ordenamiento territorial para el Caribe colombiano. (Barranquilla: Dirección de Investigaciones y Proyectos del Centro de Estudios Regionales (CERES). Universidad del Norte, 1999).

64 Ibid.

65 En la justificación de la ordenanza se encuentra, no obstante, una referencia al artículo 300 de la Constitución Política de Colombia
} 
Otro foco de legislación en este periodo es el de la ampliación de la oferta educativa. Así, por medio de la Ordenanza 16 de 1992 se autoriza el funcionamiento de Escuelas de Educación Básica General (EBG) -hasta noveno grado- y se reconoce la oficialidad de las trescientas cuarenta y siete escuelas públicas inscritas en la Secretaría de Educación departamental en ese momento. La misma ordenanza faculta a los consejos municipales para dar vida jurídica a dichas escuelas, cuyos actos administrativos serían luego aprobados por el gobernador y cofinanciados por cada municipio mancomunadamente con el departamento y la nación en línea con el Plan Departamental de Desarrollo Educativo y los planes de desarrollo municipales. El manejo de los fondos en las escuelas permanecería a cargo de los llamados Fondos de Fomento de los Servicios Docentes. Se establece, además, que en las distribuciones de recursos se tendrían en cuenta tres prioridades: 1) las Escuelas oficiales de las zonas rurales del departamento, 2) las escuelas oficiales de la zona urbano-marginales del área metropolitana de Barranquilla y las 3) escuelas oficiales de las cabeceras de los restantes municipios del Atlántico.

En 1993 se reorganizaría la distribución de los rubros presupuestales a nivel nacional. En ese mismo año, la asamblea autoriza al gobernador para suscribir convenios con el MEN para cofinanciar nuevas plazas docentes en educación secundaria (Ordenanza 40). Pero será en 1994 cuando se legisla explícitamente en torno a la nueva estructura descentralizadora, y se dictan normas orgánicas sobre la distribución de competencias para el cumplimiento de la Ley 60 de 1993 -sin que ello implicara, necesariamente, que existiese un cálculo explícito por parte del gobierno regional en torno a su capacidad de recibir dicha tarea- ${ }^{66}$. La primera ordenanza expedida en 1995 crea el Concejo Departamental de Planeación, órgano con funciones de consultoría, asesoría y supervisión del Plan Departamental de Desarrollo. A partir de este momento el departamento recibe los rubros del Sistema General de Participaciones, el cual genera esquemas de estímulos sobre la certificación para alcanzar mayores niveles de situado fiscal ${ }^{67}$. Dentro de tal lógica, los resultados en pruebas estandarizadas -ver también Ordenanza 17 de $1994^{68}$ - y los índices de cobertura, se convierten en puntos referencia en la consecución de metas educativas.

que da pistas al respecto. Éste estipula -en su versión original, antes de ser modificado a través del acto legislativo 1 de 1996- dentro de uno de sus numerales, que corresponde a las asambleas departamentales "[e]xpedir las disposiciones relacionadas con la planeación, el desarrollo económico y social, el apoyo financiero y crediticio a los municipios, el turismo, el transporte, el ambiente, las obras públicas, las vías de comunicación y el desarrollo de sus zonas de frontera".

66 En una entrevista a un supervisor de educación, funcionario de la secretaría de educación departamental cuya tarea es inspeccionar la manera en que los colegios en los territorios incorporan la legislación en su funcionamiento, salió a relucir la siguiente declaración: "cuando se aprueba la ley 60 de 1993 es la primera descentralización de recursos al departamento del Atlántico como le ocurrió a otros departamentos la nación le entregó la responsabilidad la administración del sistema educativo sin haber hecho un cálculo actuarial del Estado de las plantas físicas y las dotaciones (...) Las ordenanzas y dijeron hágase esto cómprese esto pero nunca se hizo porque no hubo plata. Por eso (...) surgió la ley 715 como una forma de poner al día ese primer proceso de descentralización porque la nación no cumplió".

67 Martha Herrera y Raúl Infante. "Las políticas públicas y su impacto en el sistema educativo colombiano. Una mirada desde los planes de desarrollo 1970-2002." Nómadas nº 20 (2004): 76-84.

68 Esta ordenanza faculta para celebrar convenios y contratos con universidades estatales y privadas para estimular a los mejores bachilleres del departamento y los mejores egresados de la Universidad del Atlántico y le da libertad para elegir criterios de escogencia que, en todo caso, deberá tener preferentemente en cuenta el puntaje obtenido en el ICFES. 
Ya en la segunda parte de la década, la Ordenanza 64 de 1996 faculta al gobernador para gestionar y configurar el programa de asistencia integral alimentaria y que para que se construyan y doten los comedores escolares en las instituciones del departamento. La Ordenanza 14 de 1997, por su parte, autoriza que se haga entrega de un lote aledaño a la Ciudadela Universitaria, y es seguida de otros actos legislativos (contenidos en la Ordenanza 34 de ese año) que se concentran en las gestiones por el crecimiento físico de este complejo. Esto podría estar relacionado con la generación de capacidades de la Universidad del Atlántico en su papel de entre rector. Finalizando la década se resalta la autorización de nuevos empréstitos por un valor de 1.789 millones de pesos para el mejoramiento y la dotación de Escuelas Departamentales (Ordenanza 28 de 1998) y la Ordenanza 41 de 1999 autoriza la suscripción de un crédito interno de 30.425,3 millones de pesos dirigidos a la planta de docentes departamentales.

\subsection{Periodo 2000-2014}

En este periodo se identificaron menos ordenanzas sobre educación (ver Gráfico 1). A finales del año 2000 se autoriza a la gobernación para realizar un nuevo empréstito de 48.539 millones de pesos para financiar la planta de docentes pertenecientes al departamento (Ordenanza 19). Se presentan a su vez modificaciones a actos legislativos vigentes, como por ejemplo la Ordenanza 24, donde se hacen adiciones al Concejo Departamental de planeación, y la Ordenanza 28, que hace una modificación a la Ordenanza 45 de 1996 para pignorar el situado fiscal de educación de rentas de Cerveza.

La primera Ordenanza de 2001 autoriza al gobierno departamental a suscribir convenios con el Ministerio de Educación Nacional y Convenios Adicionales de ejecución dirigidos hacia el Programa Nuevo Sistema Escolar Transformación de la Gestión y participación Educativa. En esta misma dirección, la Ordenanza 22 establece la enseñanza de la Educación Comunitaria a fin educar a los individuos como agentes de desarrollo de la comunidad a la cual pertenecen. Esta deberá quedar explícitamente vinculada a cada Proyecto Educativo Institucional (PEI) -respetando el principio de autonomía de las instituciones- y deberá enfatizar en aspectos curriculares de colegios y escuelas (ej. enseñanza matemática según economía regional, democrática en relación con procesos de participación de los estudiantes en asuntos de su entorno y artística para fomentar la identidad cultural). Dentro de estas disposiciones se encuentra la creación de una comisión pedagógica integrada por un grupo de asesores profesionales para la implementación de tales medidas y la autorización de estímulos (sin especificar) para exaltar establecimientos educativos que materialicen logros en indicadores curriculares de su comunidad ${ }^{69}$.

69 La única mención a la categoría recursos, vale la pena señalar, se refiere a la obligación del gobernador de realizar apropiaciones respectivas para capacitar docentes en la Catedra Comunitaria. 
Siguiendo el recorrido, la Ordenanza 6 de 2002 autoriza una modificación referente a la estampilla para financiar infraestructura sanitaria, de educación, y deportiva. La Ordenanza 29 de 2003, por su parte, autoriza al gobierno departamental a suscribir un convenio con el Sena para la capacitación de jóvenes en diferentes municipios. En 2006 la Ordenanza 8 autoriza a la Gobernación a suscribir contratos y convenios con el ICBF y los municipios del departamento para el desarrollo de programas de restaurantes escolares. Las ordenanzas 9 y 13 autorizan la suscripción de convenios interadministrativos para la dotación de infraestructura informática en las instituciones educativas del sector público. En 2007 se faculta al gobernador para abrir una licitación pública por un valor de 5.027 millones de pesos para la prestación de seis meses del servicio de vigilancia en instituciones educativas (Ordenanza 7) y se autoriza un monto de 22.266 millones para contratar la complementación del servicio educativo (Ordenanza 10). En 2008, la Ordenanza 30 otorga un rubro de 5.336 millones para contratar servicios de aseo en colegios.

En lo que resta de la década se identifican algunas iniciativas más explícitamente dirigidas a temas curriculares. Así, por ejemplo, la Ordenanza 34 de 2008 garantiza el 50\% de apropiaciones del Fondo de Comunicaciones de Atlántico Digital al programa Compromiso para un Atlántico Bilingüe, la Ordenanza 160 de 2012 busca institucionalizar el Carnaval Educativo Departamental, la Ordenanza 191 de 2013 crea la Contraloría Escolar, y la Ordenanza 213 de 2014 introduce el premio Comunidades que Aprenden, para ser celebrado cada dos años y así incentivar la buena gestión en educación de los municipios. Lo anterior, al tiempo que se sigue buscando acrecentar fuentes de financiación en rubros de aseo (Ordenanza 49 de 2009 sobre licitación de 11.641 millones de pesos y la ordenanza 198 de 2013 que autoriza y contrato de 26.919 millones y el compromiso de vigencias futuras por un monto de 23.004 millones), alimentación escolar (Ordenanza 50 de 2009) y construcción y dotación de infraestructura escolar (ordenanzas 106 de 2010 y 217 de 2014, esta última por un valor de 5.081 millones para la adhesión de un contrato con el MEN y Findeter y de contratación directa por un monto de 7.930 millones).

\section{DISCUSIÓN FINAL Y CONCLUSIÓN}

El objetivo de este artículo, vale la pena reiterarlo, es ofrecer elementos críticos para la reconstrucción de la historia reciente de la educación del Departamento del Atlántico. La historiografía tiene como fin el alimentar teorías explicativas sobre las regularidades que puedan observarse en fenómenos sociales. En este caso concreto, la incógnita gira en torno a las causas del rezago en diferentes indicadores educativos de la región y los problemas sociales y económicos que se deriven de ello.

Una primera leída de eventos históricos de la política pública educativa en Colombia permite entrever dinámicas similares entre la nación y el territorio. 
Por ejemplo, al igual que en el plano nacional, las prioridades de inversión y la producción normativa de la Asamblea Departamental del Atlántico transitan desde una óptica de cobertura y generación de capacidades institucionales sobre la regulación del sistema (entre 1980 y finales de la década de 1990), hacia debates más focalizados alrededor de la llamada calidad educativa -incluyendo elementos como la alimentación escolar y la llegada del SENA a las instituciones públicas del departamento-. Este sería un escenario alentador, en tanto denotaría esfuerzos comunes en torno a metas educativas.

Bajo dicha óptica había que inferir, sin embargo, que las políticas educativas departamentales se han visto afectadas por las contradicciones del esquema de descentralización a nivel nacional. Estas incluirían la falta de claridad entre las competencias de los actores nacionales y regionales, y el desarrollo social y económico disímil entre regiones del país. El diagnóstico desalentador sobre los logros de la región caribe en materia educativa representa un punto de referencia en sí para argumentar que el proceso descentralizador en educación dista de arrojar los resultados esperados. Una nueva lectura de los eventos históricos indicaría, por tanto, que, si bien el Departamento del Atlántico ha respaldado esfuerzos programáticos hacia la cobertura educativa, es comparativamente poco lo que se ha avanzado en torno al fenómeno de la calidad. Una forma de interpretar este fenómeno surge del análisis comparado de Grindle ${ }^{70}$, según el cual, si bien las inversiones en rubros como infraestructura pueden implicar costos financieros importantes, sus altos retornos políticos generan incentivos para que prevalezca una visión de corto plazo como principio rector del gasto.

Lo anterior podría explicar otros hechos empíricos generales, y que se plasman por descriptores cuantitativos de los gráficos 1, 2 y 3. Por ejemplo, la mayoría de las ordenanzas identificadas se remontan a los años circunstantes a la expedición de la Ley 115 de 1994 y 715 de 2001, lo que haría pensar que la actividad legisladora de la asamblea, más que estar motivada por necesidades territoriales, busca alinearse con directrices nacionales para recibir recursos de los sistemas de transferencias. En tal medida, el incremento de recursos destinados a la educación por parte del territorio (en los cuales el ítem de infraestructura es la gran constante en el tiempo) no se explicaría tanto por los mayores esfuerzos fiscales destinados a resolver problemas educativos locales, sino por la inercia misma de una mayor transferencia de recursos del sistema SGP con destinaciones específicas a educación y salud.

Llegados a este punto, es importante insistir que el análisis producido en este documento resulta insuficiente para responder a cabalidad el interrogante sobre la persistencia de problemas educativos en el caribe colombiano. Esto, en tanto, la fuente analizada permite solo explorar elementos alusivos a la construcción de la institucionalidad educativa en la región. Quedaría pendiente contrastar estos hallazgos con fuentes alusivas a las acciones y las prácticas de diferentes actores educativos (ej. servidores públicos, rectores y docentes) para contar con

70 Merilee Grindle, Going Local: Decentralization, Democratization, and the Promise of Good Governance. Princeton, New Jersey: Princeton University Press, 2007. 
una narrativa causal completa sobre los procesos de (re)producción de dinámicas educativas en la región [ver, por ejemplo, Parra y Correa ${ }^{71}$. Pese a ello, el ejercicio desarrollado en el artículo permite inferir que los incentivos institucionales que enfrentan dichos actores se alinean con una búsqueda pasiva por cumplir los requisitos formales de la descentralización, en un marco de acciones limitadas para poner en marcha principios de autonomía y gobierno basados en necesidades locales concretas.

\section{REFERENCIAS}

Archer, Margaret. Realist social theory: the morphogenetic approach. Cambridge: Cambridge University Press, 1995.

Barrera-Osorio, Felipe. "La política de educación en Colombia 1957-2004." Coyuntura Económica XXXV, no. 2 (2005): 307-314.

Barrera-Osorio, Felipe, Darío Maldonado, y Catherine Rodriguez. "Capítulo 4. Calidad de la educación básica y media en Colombia: diagnóstico y propuestas." En Equidad y movilidad social. Diagnósticos y propuestas para la transformación de la sociedad colombiana, de A Montenegro y M Meléndez, 239-330. Bogotá: Universidad de los Andes, 2014.

Bell, Gustavo, y Alexandra García. Costos y Beneficios de dos modelos de ordenamiento territorial para el Caribe colombiano. Barranquilla: Dirección de Investigaciones y Proyectos del Centro de Estudios Regionales (CERES). Universidad del Norte, 1999.

Bonet, Jaime, Gerson Pérez, y Jhorland Ayala. Contexto histórico y evolución del SGP en Colombia. Cartagena: Documentos de Trabajo Sobre Economía Regional. Banco de la República, 2014.

Bonet, Jaime, y Adolfo Meisel. "Regional economic disparities in Colombia." Journal of Regional Research 14 (2009): 61-80.

Cajiao, Francisco. "La concertación de la educación en Colombia." Revista Iberoamericana de Educación, no. 34 (2004): 31-47.

Chamorro, Diana, Mónica Borjas, y Jorge Valencia. "Básica y Media." En Situación de la educación en el caribe colombiano 2008-2011, de Elias Said, 53-105. Barranquilla: Observatorio de Educación del Caribe Colombiano (OECC) de la Universidad del Norte, 2013.

Collier, Andrew. In Defence of Objectivity and Other Essays on Realism, Existentialism and Politics. Londrés y Nueva York: Routledge, 2003.

Correa de Andreis, Alfredo. "La región en la historia doble de la Costa." En Sociología desde el Caribe colombiano. Mirada de un sentimpensante, de Jair Vega, 229-233. Barranquilla: Universidad del Norte, 2016.

De la Calle, Humberto. “Las ilusiones fallidas de la descentralización.” En Memorias del Seminario 20 años de la descentralización en Colombia: presente y futuro, de Darío Restrepo, 132-137. Bogotá: Red de Iniciativas para la Gobernabilidad, la Democracia y el Desarrollo Territorial - RINDE, 2007.

DNP y ESAP. Las Asambleas Departamentales y su papel en la gestión pública para el desarrollo. Bogotá: Guías para la gestión pública territorial. Departamento Nacional de Planeación, 2011.

Fals-Borda, Orlando, y Miguel Borja. "Guía práctica del Ordenamiento Territorial en Colombia." Revista Foro 36 (1999): 74-92.

Gómez-Buendía, Hernando. Educación en América Latina y el Caribe: la Agenda del siglo XXI. Bogotá: Programa de Naciones Unidas para el Desarrollo, PNUD, 1998.

Grindle, Merilee. Going Local: Decentralization, Democratization, and the Promise of Good Governance. Princeton, New Jersey: Princeton University Press, 2007.

Gutiérrez, Francisco. "Instituciones y territorio. La descentralización en Colombia." En 25 años de la

71 Parra, Juan David, y Gustavo Correa. "Reflexiones sobre los retos de la política educativa en el caribe colombiano: una indagación en prensa." Revista Papeles 10, no. 19 (2018): 56-70. 
descentralización en Colombia, 11-54. Bogotá: Konrad Adenauer Stifttung, 2010.

Hanson, E Mark. "Administrative Development in the Colombian Ministry of Education: A Case Analysis of the 1970s." Comparative Education Review 27, no. 1 (1983): 89-107.

Hanson, E Mark. "Democratization and Decentralization in Colombian Education." Comparative Education Review 39, no.1 (1995): 100-119.

Helg, Aline. La educación en Colombia, 1958-1980. Vol. IV, de Nueva historia de Colombia, de Álvaro Tirado Mejía, 135-158. Bogotá: Planeta Colombiana Editorial, 1986.

Henríquez, Hermes de Jesús. "Politicas públicas en educación y desarrollo en la Región Caribe." Revista de Economía del Caribe 12 (2013): 217-246.

Herrera, Martha, y Raúl Infante. “Las políticas públicas y su impacto en el sistema educativo colombiano. Una mirada desde los planes de desarrollo 1970-2002." Nómadas, no. 20 (2004): 76-84.

Iregui, Ana María, Ligia Melo, y Jorge Ramos. “La educación en Colombia: análisis del marco normativo." Revista de Economía del Rosario 9, no. 2 (2006): 175-238.

Kalmanovitz, Salomón. Nueva Historia Económica de Colombia. Bogotá: Taurus, 2010.

Meade, Ben, y Alec Ian Gershberg. "Making education reform work for the poor: accountability and decentralization in Latin America." Journal of Education Policy 23, no. 8 (2008): 299-322.

Miesel, Adolfo. "Albert O. Hirschman y los desequilibrios económicos regionales: de la economía a la política, pasando por la antropología y la historia." Desarrollo y Sociedad 62 (2008): 203223.

Montoya-Vargas, Juny. "The Field of Curriculum Studies in Colombia." En International Handbook of Curriculum Research Vol 2, de W Pinar, 134-150. Routledge, 2014.

Mundy, Karen, y Antoni Verger. "The World Bank and the global governance of education in a changing world order." International Journal of Educational Development 40, no. January (2015): 9-18.

Mutch, Alistair. "History and Documents in Critical Realism." En Studying organizations using Critical Realism: A practical guide, de Paul Edwards, Joe Mahoney y Steve Vincent, 223-240. Oxford: Oxford University Press, 2014.

Ocampo, José Antonio, Carmen Astrid Romero, y María Angela Parra. “La búsqueda, larga e inconclusa, de un nuevo modelo (1981-2006)." En Historia económica de Colombia: edición revisada y actualizada, de José Antonio Ocampo, 341-418. Bogotá: Editorial Planeta, 2007.

Ocampo, José Antonio, Mauricio Avella, Jaoquín Bernal, y María Errázuriz. “La industralización y el intervencionismo estatal (1945-1980)." En Historia económica de Colombia: edición revisada y actualizada, de José Antonio Ocampo, 271-340. Bogotá: Editorial Planeta, 2007a.

Palacios, Marco, y Frank Safford. Colombia: Fragmented Land, Divided Society. Nueva York: Oxford University Press, 2002.

Parada, Jairo. "Desarrollo regional y desarrollo institucional en la costa atlántica." Ensayos de Economía 2, no. 1 (1991): 29-36.

Parada, Jairo. Instituciones, desarrollo y regiones. El caso de Colombia. Barranquilla: Universidad del Norte, 2013.

Parra, Juan David. "Critical realism and school effectiveness research in Colombia: The difference it should make. " The British Journal of Sociology of Education 39, no. 1 (2018): 107-125.

Parra, Juan David. "El reto de la descentralización educativa: reflexiones desde la mirada de actores nacionales y subnacionales en el caso del departamento del Atlántico." Papel Político 22, no. 2 (2017): 339-367.

Parra, Juan David. "Realismo crítico: una alternativa en el análisis social." Sociedad y Economía, no 31 (2016): 215-238.

Parra, Juan David. "The Paradigm of Critical Realism and Involving Educators in Policy Debates." GIST Education and Learning Journal, no. 10 (2015): 149-171.

Parra, Juan David, y Gustavo Correa. "Reflexiones sobre los retos de la política educativa en el caribe colombiano: una indagación en prensa." Revista Papeles 10, no. 19 (2018): 56-70.

Patomäki, Heikki. "A critical realist approach to global political economy." En Critical Realism. The difference it makes, de J Cruickshank, 197-220. Londres and Nueva York: Routledge, 2003.

Ramírez, María Teresa, y Juana Patricia Téllez. “La educación primaria y secundaria en Colombia 
en el siglo XX." En Economía Colombiana del siglo XX: un análisis cuantitativo, de James Robinson y Miguel Urrutia, 459-517. Bogotá: Fondo de Cultura Económica, 2007.

Said-Hung, Elias, y Jorge Valencia. Resultados en las pruebas de Estado en la región Caribe colombiana 2009 - 2012. Barranquilla: Observatorio de Educación del Caribe Colombiano (OECC) de la Universidad del Norte, 2014.

Sewell, William. "Historical events as transformations of structures: Inventing revolution at the Bastille." Theory and Society 25, no. 6 (1996): 841-881.

Soifer, Hillel. State Building in Latin America. Nueva York: Cambridge University Press, 2015.

Steinmetz, George. "Critical Realism and Historical Sociology. A Review Article." Comparative Studies in Society and History 40, no. 1 (1998): 170-186.

Torres, Juan Carlos, y Horacio Duque. "El proceso de descentralización educativa en Colombia." Revista Colombiana de Educación 29 (1994): 7-50.

Vanegas, Patricia. “The Northern Influence and Colombian Education Reform of the 1990s." En Crisis and Hope. The Educational Hopscotch of Latin America, de Stephen J Ball, Gustavo E Fischman y Silvina Gvirtz, 227-250. Nueva York y Londres: Routledge, 2003.

Villar, Leonardo, y otros. Sistema General de Participaciones y su vínculo con las políticas e incentivos dirigidos a la excelencia docente y el mejoramiento continuo de la calidad de la educación. Bogotá: Fundación para la Educación Superior y el Desarrollo (Fedesarrollo), 2016.

Vincent, Steve, y Robert Wapshott. “Critical Realism and the Organizational Case Study: A Guide to discovering Institutional mechanisms." En Studying Organizations Using Critical Realism. A Practical Guide, de Paul Edwards, Joe O'Mahoney y Steven Vincent, 148-167. Oxford: Oxford University Press, 2014.

Wickham, Chris. “The Problems of Comparison." Historical Materialism 19, no. 1 (2011): 221-231.

Willmott, Robert. "Structure, Agency and the Sociology of Education: Rescuing analytical dualism." British Journal of Sociology of Education 20, no. 1 (1999): 5-21.

\section{Cómo citar:}

Correa, Gustavo; Parra Heredia, Juan David. “Historia reciente de la educación básica y media en el caribe colombiano: El caso del Departamento del Atlántico" Revista Historia de la Educación Latinoamericana. Vol. 21 No. 32 (2019): 247-271

https://doi.org/10.19053/01227238.9389

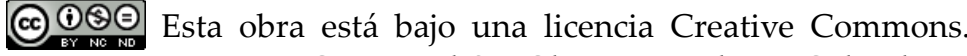
Reconocimiento-No Comercial-Sin Obra Derivada 2.5 Colombia. 
Anexo. Estrategias utilizadas para buscar ordenanzas faltantes y precisar algunos conceptos

\begin{tabular}{|c|c|c|}
\hline $\begin{array}{l}\text { Observación del } \\
\text { investigador }\end{array}$ & Descripción del problema & Implicación o solución \\
\hline $\begin{array}{l}\text { Ordenanzas in- } \\
\text { determinadas. }\end{array}$ & $\begin{array}{l}\text { Ordenanzas que no tenían in- } \\
\text { formación que sirviera para } \\
\text { identificar su fecha de expedi- } \\
\text { ción. }\end{array}$ & $\begin{array}{l}\text { En casos donde la ordenanza no } \\
\text { tenía información de fecha escri- } \\
\text { ta en el documento original, pero } \\
\text { que estaba archivada en una car- } \\
\text { peta de un año específico, se con- } \\
\text { firmó con el administrador del } \\
\text { archivo si era válido asumir que la or- } \\
\text { denanza en efecto pertenecía a ese año. } \\
\text { En casos donde la ordenanza no tuvie- } \\
\text { ra esta información, y estuviera archi- } \\
\text { vada fuera de una carpeta específica, } \\
\text { se indagó con el administrador del } \\
\text { archivo en dónde ubicarla. Si el admi- } \\
\text { nistrador no tenía esa información, se } \\
\text { archivaba como ordenanza indetermi- } \\
\text { nada. }\end{array}$ \\
\hline $\begin{array}{l}\text { Concepto de Es- } \\
\text { cuela. }\end{array}$ & $\begin{array}{l}\text { Durante la primera revisión el } \\
\text { investigador encontró un uso } \\
\text { mixto del término escuela y } \\
\text { colegio. }\end{array}$ & $\begin{array}{l}\text { Tras una entrevista con supervisores } \\
\text { de educación (funcionarios de la Se- } \\
\text { cretaría de Educación Departamental } \\
\text { que inspeccionan instituciones edu- } \\
\text { cativas) se hizo la aclaración. Escuela } \\
\text { es un término que se utiliza para re- } \\
\text { ferirse a instituciones educativas ge- } \\
\text { neralmente ubicadas en zonas rurales } \\
\text { y que ofrecen educación de grados } 0 \\
\text { a } 9 \text { en educación básica y media. Los } \\
\text { colegios ofrecen el ciclo educativo } \\
\text { completo, incluyendo grados } 10 \text { y } 11 \text {. } \\
\text { En casos muy particulares cuando la } \\
\text { escuela hacía referencia otro tipo de } \\
\text { institución (ej. Escuela de Ingenieros), } \\
\text { se hicieron búsquedas en internet para } \\
\text { aclarar naturaleza de la institución. }\end{array}$ \\
\hline Presupuestos. & $\begin{array}{l}\text { Ordenanzas que incluyen in- } \\
\text { formación sobre destinaciones } \\
\text { específicas dentro del presu- } \\
\text { puesto general del departa- } \\
\text { mento. }\end{array}$ & $\begin{array}{l}\text { Estas ordenanzas fueron archivadas } \\
\text { en una carpeta específica de presu- } \\
\text { puestos, y se utilizaron para buscar in- } \\
\text { formación cuantitativa sobre ingresos } \\
\text { y gastos. Un reto de esta tarea es que } \\
\text { los presupuestos no son uniformes en } \\
\text { estructura ni en cuanto a la forma en } \\
\text { que se nombran las partidas presu- } \\
\text { puestales dentro de los mismos. }\end{array}$ \\
\hline
\end{tabular}



caribe colombiano: el caso del Departamento del Atlántico

\begin{tabular}{|c|c|c|}
\hline $\begin{array}{l}\text { Observación del } \\
\text { investigador }\end{array}$ & Descripción del problema & Implicación o solución \\
\hline $\begin{array}{l}\text { Ordenanzas que } \\
\text { modifican otras } \\
\text { ordenanzas. }\end{array}$ & $\begin{array}{l}\text { En la medida que el archivo no } \\
\text { estaba completo, no siempre es } \\
\text { posible identificar ordenanzas } \\
\text { que son modificadas, según se } \\
\text { hace referencia en una orde- } \\
\text { nanza específica. }\end{array}$ & $\begin{array}{l}\text { Se hicieron anotaciones sobre las mo- } \\
\text { dificaciones y, cuando es relevante se } \\
\text { mencionan modificaciones que pue- } \\
\text { dan ayudar a develar tendencias ins- } \\
\text { titucionales en materia de decisiones } \\
\text { educativas. }\end{array}$ \\
\hline $\begin{array}{l}\text { Proyectos de Or- } \\
\text { denanzas. }\end{array}$ & $\begin{array}{l}\text { Son pocos los casos, pero algu- } \\
\text { nos archivos estaban titulados } \\
\text { proyecto de ordenanza. Como } \\
\text { tal, no son documentos oficia- } \\
\text { les. }\end{array}$ & $\begin{array}{l}\text { Estos fueron archivados en el archivo } \\
\text { general del proyecto, pero su conteni- } \\
\text { do no se considera como oficial. }\end{array}$ \\
\hline $\begin{array}{l}\text { Autorización y } \\
\text { Empréstito. }\end{array}$ & $\begin{array}{l}\text { Confusión sobre estos térmi- } \\
\text { nos durante lectura de docu- } \\
\text { mentos. }\end{array}$ & $\begin{array}{l}\text { Se aclaró con consultas a adminis- } \\
\text { tradores y búsqueda en internet que } \\
\text { estos son términos que expresan } \\
\text { una autorización que se le hace } \\
\text { al Gobernador departamental, o } \\
\text { funcionario en mención, para suscribir } \\
\text { deudas financieras que permitan dar } \\
\text { cumplimiento a metas de inversión. }\end{array}$ \\
\hline $\begin{array}{l}\text { Ordenanzas au- } \\
\text { sentes o difíciles } \\
\text { de consultar. }\end{array}$ & $\begin{array}{l}\text { En la primera fase de recolec- } \\
\text { ción se identificaron algunos } \\
\text { vacíos en materia de infor- } \\
\text { mación (ordenanzas faltantes } \\
\text { o indeterminadas). Los años } \\
\text { con más vacíos en información } \\
\text { fueron: 1986, 1987, 1988, 1989, } \\
\text { 1990, 1991, 2005,2006, 2007, } \\
2008,2009,2012,2014.2005 \text { es } \\
\text { el único en el cual no se encon- } \\
\text { traron ordenanzas. }\end{array}$ & $\begin{array}{l}\text { Se presentó un oficio con fecha del } \\
\text { 03/03/15 solicitando aclaraciones al } \\
\text { administrador del archivo. Los resul- } \\
\text { tados del ejercicio de revisión fueron: } \\
\text { - Se confirma que para el } 2005 \text { no hay } \\
\text { registros de ordenanzas. De acuerdo } \\
\text { con el administrador del archivo es } \\
\text { posible que estas ordenanzas faltan- } \\
\text { tes se encuentren en otras instancias, } \\
\text { como por ejemplo el archivo de la go- } \\
\text { bernación. } \\
\text { - Una revisión general al periodo } \\
\text { 1986-1991 permitió identificar algunas } \\
\text { ordenanzas inicialmente declaradas } \\
\text { faltantes. } \\
\text { - De acuerdo con el administrador del } \\
\text { archivo, las ordenanzas de } 2008 \text { a 2014 } \\
\text { son de valor primario (término utiliza- } \\
\text { do en archivística para identificar do- } \\
\text { cumentos que tienen utilidad dentro } \\
\text { de una oficina de gobierno). La mayo- } \\
\text { ría de estas ordenanzas se encuentran } \\
\text { en la Secretaría de la Asamblea. Sin } \\
\text { embargo, se abrió un espacio de una } \\
\text { tarde para que los investigadores con- } \\
\text { sultaran estos archivos. Otros de estos } \\
\text { (los años más recientes) se encuentran } \\
\text { para consulta en internet. }\end{array}$ \\
\hline
\end{tabular}

